\title{
Nondestructive Analysis of Au-Cr Layers in Aged Microcircuits
}

\author{
Arlyn Antolak, Daniel Morse, Kenneth Wilson \\ Sandia National Laboratories \\ RECEIVED \\ Livermore, CA

$$
\text { CONF- } 970982-\text { SEP } 261997
$$

Abstract

Particle-induced $x$-ray emission (PIXE), Rutherford backscattering spectroscopy (RBS), and nuclear reaction analysis (NRA) are being used to investigate compositional changes in MK4 radar unit microelectronics resulting from possible age-related chromium diffusion in gold. Since the analysis is nondestructive, changes in the mechanical properties of the system can be more readily correlated to measured compositional changes at the buried interface. Measurements are conducted to investigate trace levels of chromium at the external Au surface, determine the actual gold layer thickness of the test sample, and measure compositional changes occurring at the $\mathrm{Au}-\mathrm{Cr}$ interface.

\section{INTRODUCTION}

MC2823 microcircuits in MK4 radar units are comprised of a 3-6 micron gold layer bonded to a thin $500 \AA \mathrm{Ta}_{2} \mathrm{~N}$ layer using $300 \AA$ of $\mathrm{Cr}$ as an adhesive layer (see figure 1). Since it is known that $\mathrm{Cr}$ readily diffuses through the grain boundaries of polycrystalline $\mathrm{Au}$ films at elevated temperatures ${ }^{1}$, it is reasonable to assume that similar changes could occur at room temperature over long periods of time. In some of the elevated temperature studies, extensive out-diffusion was seen including complete depletion of the chromium adhesive layer with the formation of channeled grain boundaries occupied by $\mathrm{Cr}_{2} \mathrm{O}_{3}$. The grain boundary diffusion coefficient has been reported to be approximately $6 \times 10^{-12}$ to $4 \times 10^{-15} \mathrm{~cm}^{2} \mathrm{~s}^{-1}$ at $300^{\circ} \mathrm{K}$ with an activation energy in the range 0.9 to $1.5 \mathrm{eV}{ }^{2,3}$ Eventually, single crystals of $\mathrm{Cr}_{2} \mathrm{O}_{3}$ formed and were observed on the gold surface. The compositional changes associated with the diffusing $\mathrm{Cr}$ lead to changes in the electrical

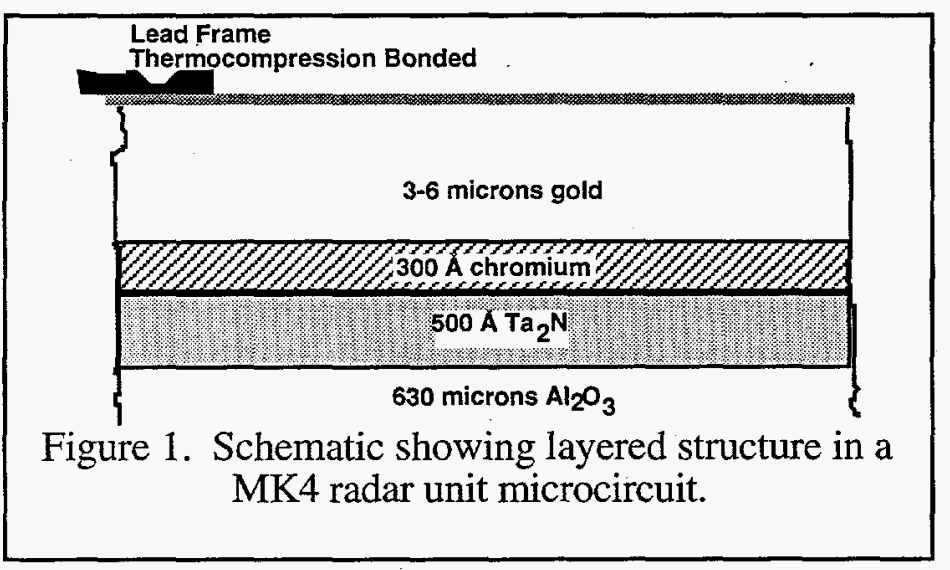
properties of the gold, e.g., increased electrical resistivity, while the oxidation of chromium to $\mathrm{Cr}_{2} \mathrm{O}_{3}$ can lead to adhesion failures.

A 17 year old radar unit was recently recovered from the stockpile and made available for analysis. Standard nondestructive techniques such as scanning electron microscopy (SEM) or $\mathrm{x}$-ray fluorescence (XRF) cannot characterize the buried interface because the thick gold layer either prevents the incident probing beam from reaching the $\mathrm{Au}-\mathrm{Cr}$ interface or causes the emission signal to be absorbed before it can be detected (matrix effects). On the other hand, nuclear microscopy uses high energy focused ion beams for nondestructive materials characterization. Scanned particle-induced x-ray emission (PIXE) analysis is routinely used for measuring trace impurities and stoichiometric variations in samples with micron-scale spatial resolution and, in some cases, ppm sensitivities. Rutherford backscattering spectroscopy (RBS) uses the measured energies and intensities of scattered recoils from incident ion bombardment for sensitive elemental/isotopic depth profiling of layered structures and for film thickness determination. Nuclear reaction analysis (NRA) provides elemental or isotopic concentrations as a function of depth. In the latter technique, buried layers can be probed by detecting the highly penetrating gamma-rays emitted by the elements in the layer after ion bombardment. We are applying these nuclear microscopy techniques to nondestructively profile the chromium distribution and to determine the extent of age-related compositional changes at the buried interface. These data can be correlated to changes in the mechanical properties of the system which ultimately lead to better models for predicting age-related effects in these components. 


\section{DISCLAIMER}

This report was prepared as an account of work sponsored by an agency of the United States Government. Neither the United States Government nor any agency thereof, nor any of their employees, makes any warranty, express or implied, or assumes any legal liability or responsibility for the accuracy, completeness, or usefulness of any information, apparatus, product, or process disclosed, or represents that its use would not infringe privately owned rights. Reference herein to any specific commercial product, process, or service by trade name, trademark, manufacturer, or otherwise does not necessarily constitute or imply its endorsement, recommendation, or favoring by the United States Government or any agency thereof. The views and opinions of authors expressed herein do not necessarily state or reflect those of the United States Government or any agency thereof. 


\section{DISCLAMIXR}

Portions of this docament mey be illegible in electronic image prodnets. Images are produced from the best available original docoment 


\section{EXPERIMENT}

We presently operate two nuclear microprobes for trace element analysis, elemental depth profiling, and three-dimensional tomographic imaging of samples. As mentioned above, particleinduced $\mathrm{x}$-ray emission (PIXE) is used for trace element analysis and thin film thickness determination. PIXE is a fluorescence-based technique similar in principal to electron probe X-ray microanalysis (EPXMA) but with much lower detection limits. The enhanced sensitivity is due to the fact that high energy ion beams produce about 100 times less Bremsstrahlung background than what is produced by an electron beam. Two-dimensional maps of elemental concentration are obtained by recording the energies and intensities of emitted characteristic $\mathrm{x}$-rays as the focused ion (proton) beam is rastered across the sample surface. Because chromium X-rays $(5.4 \mathrm{keV})$ are significantly attenuated in gold, PIXE is sensitive to $\mathrm{Cr}$ only in the near surface region of the samples. For example, the sensitivity to $\mathrm{Cr}$ at a depth of 0.5 microns in gold is half as much as at the surface and at 3 microns depth the sensitivity is reduced about four orders of magnitude. The detection limit for chromium in gold by PIXE is limited to about $100 \mathrm{ppm}$ because a large number of gold x-rays must be processed in order to establish a reasonable $\mathrm{Cr}$ signal. On the other hand, probing the near surface of the gold layer by PIXE provides a rapid initial indicator of whether extensive diffusion has occurred, i.e., if $\mathrm{Cr}$ has migrated completely through the gold layer to form localized concentrations of $\mathrm{Cr}_{2} \mathrm{O}_{3}$.

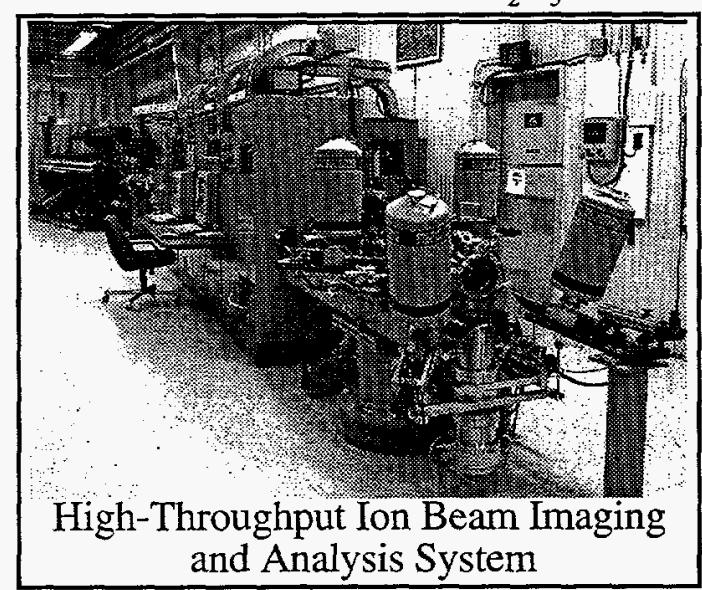

Nuclear reaction analysis (NRA) is a technique to nondestructively determine the $\mathrm{Cr}$ profile at the buried Cr-Au interface. For example, Switkowski and coworkers have used the resonance in the ${ }^{52} \mathrm{Cr}(\mathrm{p}, \gamma){ }^{53} \mathrm{Mn}$ reaction at a proton energy of 1.005 $\mathrm{MeV}$ for quantifying chromium depth distributions in chrome-black solar absorber surfaces. ${ }^{4}$ The photopeak yield of $378 \mathrm{keV}$ gamma-rays corresponding to the first excited state to ground state transition in ${ }^{53} \mathrm{Mn}$ is proportional to the $\mathrm{Cr}$ concentration. Based on published branching ratio data, approximately $69 \%$ of all gamma-ray cascades feed this first excited state. ${ }^{5}$ A normally incident $1.67 \mathrm{MeV}$ proton beam will lose 665 $\mathrm{keV}$ after traversing 6 microns of gold; a $1.37 \mathrm{MeV}$ beam will lose $360 \mathrm{keV}$ in 3 microns of gold. Thus, an accurate measurement of the Au layer thickness is required to optimize the ion beam energy for NRA. In the present study, the gold layer thickness in the test sample is measured by Rutherford backscattering spectroscopy. The estimated depth resolution by NRA will vary from a few hundred Angstroms at the surface to around $0.25 \mu \mathrm{m}$ at $6 \mu \mathrm{m}$ in gold due to range straggling of the incident proton beam. The main limitation of NRA is the relatively low cross section of this particular reaction which would limit the sensitivity to roughly percent levels.

\section{RESULTS}

PIXE data were collected and analyzed from an aged MK4 radar unit microcircuit sample. The spectrum (dotted line) from the PIXE analysis of the near surface of the sample is shown in Figure 2. The data were collected with a $3 \mathrm{MeV}$ proton beam focussed to a spot size of 100 microns. Also shown are the calculated fits to the background (dashed line) and x-ray peak shapes (solid line). Except for the strong Au emission lines, the only other clearly distinguishable x-rays are from iron. The iron signal was found to be caused from secondary fluorescence of the stainless steel target chamber by the Au X-rays. The location of the $\mathrm{Cr} \mathrm{K}$-lines is indicated in the figure, but their yield is negligible at the detection limits of the experiment (approximately $100 \mathrm{ppm}$ ). Subsequent measurements made on a high purity copper standard confirmed that the chromium and iron $\mathrm{X}$-rays in the PIXE spectra were produced by secondary fluorescence of the target chamber ( $\mathrm{Cu} \mathrm{K} \mathrm{X}$-rays have comparable energies to $\mathrm{Au} \mathrm{L} \mathrm{X}$-rays). Thus, it appears that $\mathrm{Cr}$ has not diffused to the external gold surface in any significant amount (at least in the area scanned on this sample). 
Figure 3 shows RBS spectra collected on the aged microcircuit sample and on a 7.25 micron thick

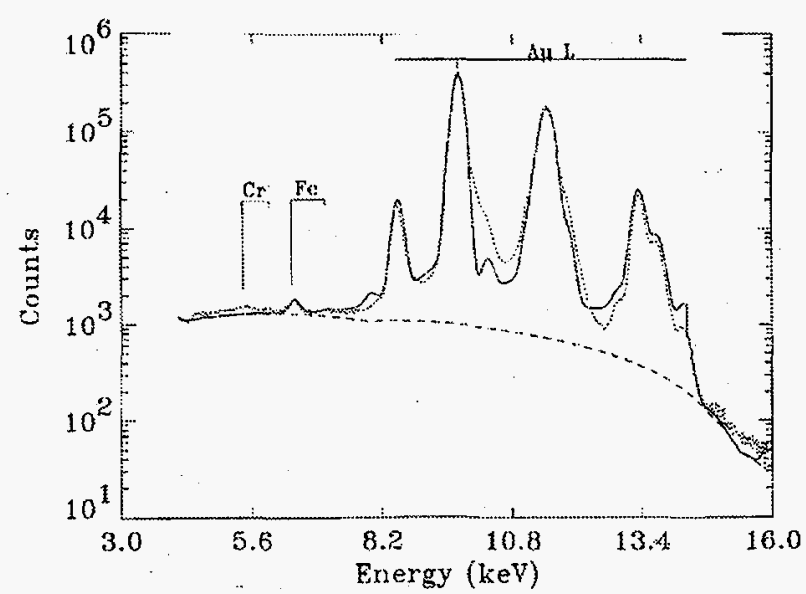

Figure 2. PIXE spectra from an aged Au-Cr microcircuit sample. The dotted line is the raw data, the calculated background is shown as a dashed line, and the fit to the $\mathrm{x}$-ray peaks is the solid line. gold foil (on a Fe-Ni-Co alloy substrate) standard used to calibrate the thickness measurement. The spectra were collected using a $3 \mathrm{MeV}$ normally incident proton beam focussed to a spot size of $10 \mu \mathrm{m}$ and an annular silicon surface barrier detector located at a scattering angle of $175^{\circ}$. The peak in each spectrum at high energy is due to scattering from gold while the peaks at lower energies are from the substrate materials. These data indicate that the gold layer thickness in the microcircuit is approximately $7.5 \mu \mathrm{m}$.

Chromium profiling with NRA requires some standard modifications to our existing ion beam system such as incorporating a thick germanium gammaray detector and integrating the appropriate software for data acquisition. After these modifications are completed, samples must be calibrated and sensitivity studies conducted for determining low level $\mathrm{Cr}$ concentrations in Au. Analysis times are significantly longer due to the low reaction cross sections. In order to measure the $\mathrm{Cr}$ concentration versus depth, it will be necessary to collect a series of measurements with varying proton energies. Work is in progress to accomplish the system modifications and collect the NRA data.

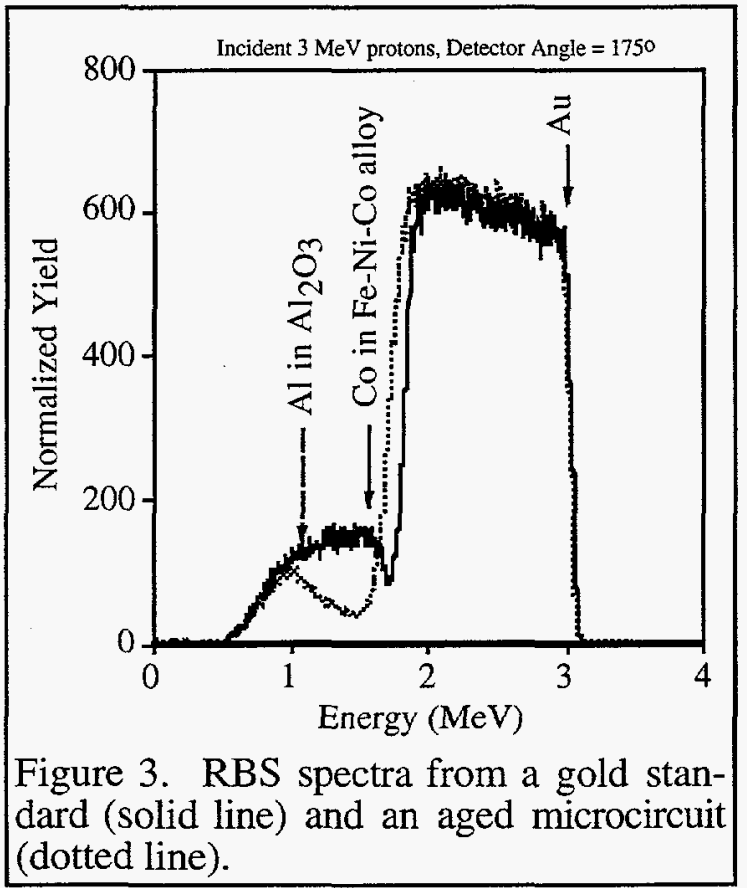

\section{SUMMARY}

Nuclear microscopy provides the capability to determine the extent of $\mathrm{Cr}$ migration through gold in aged microcircuit conductor layers in a nondestructive manner. Preliminary measurements on a localized region of the aged microcircuit sample have revealed little or no $\mathrm{Cr}$ (from $\mathrm{Cr}_{2} \mathrm{O}_{3}$ ) at the external Au surface. Additional investigations have determined the gold layer thickness to be $7.5 \mu \mathrm{m}$ compared to the specified nominal values of 3-6 $\mu \mathrm{m}$. Measurements have also begun to nondestructively profile the distribution of $\mathrm{Cr}$ at the buried $\mathrm{Au}-\mathrm{Cr}$ interface.

\section{ACKNOWLEDGEMENTS}

The authors would like to thank D.P. Norwood, 1471 for providing the sample for analysis. We gratefully acknowledge support of this work by the SNL Material Science Research Foundation.

\section{REFERENCES}

${ }^{1}$ M.A. George et al., Thin Solid Films 189 (1990) 59.

${ }^{2}$ A. Munitz and Y. Komem, Thin Solid Films 37 (1976) 171.

${ }^{3}$ L.S. Weinman et al., Thin Solid Films 72 (1980) 183.

${ }^{4}$ Z.E. Switkowski et al., Nucl. Instr. Meth. 159 (1979) 407.

${ }^{5}$ R.L. Schulte et al., Nucl. Phys. A243 (1975) 202. 